\title{
Virtual Reality Cataloguing of Light Installations and Environments: The prototypes of Dan Flavin and Ann Veronica Janssens
}

\author{
Leticia Crespillo Marí \\ Universidad de Málaga \\ Avda. Cervantes, 2. 2071, Málaga, \\ Spain \\ Icrespillom@uma.es
}

\section{INTRODUCTION}

At present it is necessary to replace several catalogue registration methods, especially when we talk about interactivity, immersion and corporealization as fundamental characteristics of a particular artistic manifestation. A two-dimensional support or dynamic audiovisual image is not enough. An update is therefore required in the way in which the contents are collected and disseminated in order to create a more complete knowledge of the work of art. Contemporary light installations and environments propose using a three-dimensional paradigm of presence related to affective learning and the requirement of exploration. The Virtual technology can help us to developing this kind of useful tools in the field of active reception, especially when we are in front of an intervention with an aesthetic, phenomenological, cognitive and somatic character that also uses a plastic intangible element as is the light. In this field, the virtual will allow to develop own, intimate and unique aesthetic experiences with a great affective component through the design of a navigable 3D. This model is implementing with the catalogue information necessary to know in depth these both works, from a formal and aesthetic point of view. Thus, in this article, some research results related to the development of two virtual prototypes of Installation and Environment, Dan Flavin and Ann Veronica Janssens respectively which are shown as a first step towards the implementation of a virtual alternative of registration.

\section{VIRTUAL PARAMETERS: IMMERSIVE PARTICIPATION AND AFFECTIVE-COGNITIVE LEARNING}

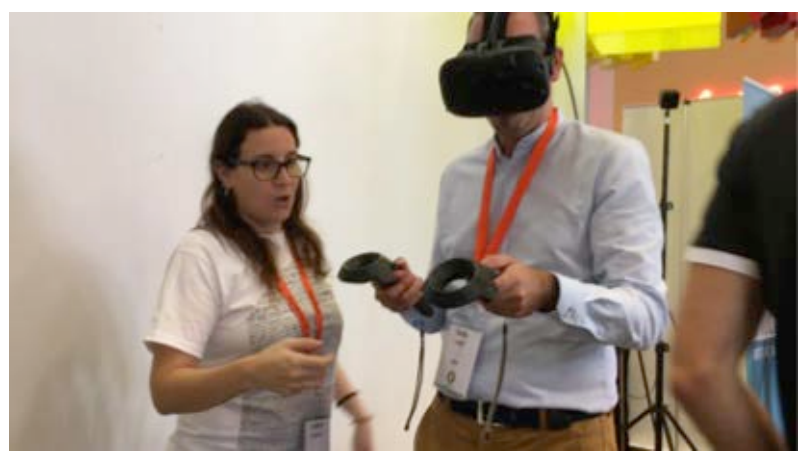

Figure 1: Leticia Crespillo at the New Tech Observatory explaining how testing the prototype to a person. Polo de contenidos digitales, Málaga, July, 2019.

Virtual Reality interests us because, like the installations and lighting environments, it is constantly updated with each subjective participation of a spectator. The interface translates the representation as if it were real, and inserts the subject's body into the model, expanding the affective and cognitive narrative universe through artistic language. These manifestations have a theatrical character that surrounds the viewer, something necessary to understand this type of work. The virtual image itself becomes a conceptual construction allowing, as Jorge Iván Suárez indicates "to get a plastic-expressive expression of the phenomenon in an environment designed and developed for active work-spectator participation. 
Subjective experience remains a vital issue from the point of view of cognitive science. In the field of the humanities and, more specifically, Art History is beginning to investigate about the cortical nervous activation before a work of art. The somatic involvement of the body becomes another way of experience and understanding of this type of phenomenological and space-time works. The body is a physical and conscious one as well and, as such, it contributes and completes performative and processual way the visual perception before a three-dimensional installation or environment. Therefore, Virtual Reality updates this approach allowing the viewer, not only to know the work at a descriptive level in an image, but to dive inside, to be the protagonist of his own experience when it is not possible to explore it in situ. In this way it is possible to create a much more complete and complex knowledge about it, establishing a neurological and biological continuity with which you can study the different behaviours that arise before the same image or the same artistic space. Contemporary light installations and environments show us a clear influence on the psychology of the viewer, which is why it is so important to experience them through mental and bodily presence. The perceptual phenomenon in front of an aesthetic representation of these characteristics encodes a series of cognitive relationships based on movement. As a result, empathy arises and, with it, affective learning where memory plays an important role revealing prior knowledge structures that give some meaning to what the viewer is contemplating.

\section{INSTALLATIONS AND ENVIRONMENTS REPRESENTATIVE PHENOMENOLOGICAL SPACES OF EXPERIENCE, LEARNING, EMOTION AND MEMORY}

These types of light interventions in space have a relevant role in the memory of past stimuli. The body is a direct link of experience and, on a somatic level, it makes us feel relationships with the world. The metaphor as a three-dimensional spatial construction through the use of light establishes a dialogue with the viewer where the material passes to the background and the phenomenon of aesthetic experimentation is defined as part of the conceptual map of our experience. Virtual Reality does not differ much from how these manifestations of art work. Its immersive, participatory, spatial, temporal, corporal and interactive character allows the aesthetic encounter with the viewer with the phenomenon that happens there. Thus, own coordinates are determined that multiply and reaffirm with each.

\section{THE PROTOTYPES OF DAN FLAVIN AND ANN VERONICA JANSSENS: RESULTS AND CONCLUSIONS}

As part of my PhD. at the University of Malaga (Spain), I have been working in a two prototypes in Virtual Reality with Opossum Studios Virtual Builders (Melilla, Spain). These models are a Dan Flavin's light Installation, Untitled (to Helga and Carlo, with respect and affect), 1974 from the David Zwirner Gallery (New York) and the light environment of Ann Verónica Janssens Yellowbluepink, 2015 from the Wellcome Collection (London) which is part of the States of Mind project. Both models have been made from the technical descriptions of the catalogues in question.

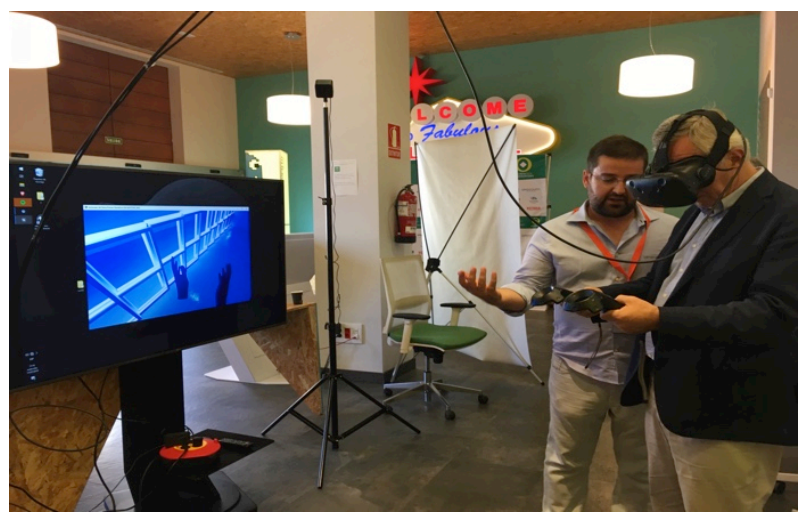

Figure 2: Grabriel Gonzálvez (C.E.O Opossum Studios) explaining to José Lebrero Stals (Chair of Picasso's Museum, Málaga) testing the Dan Flavin's prototype. Polo de contenidos digitales, Málaga, July, 2019.

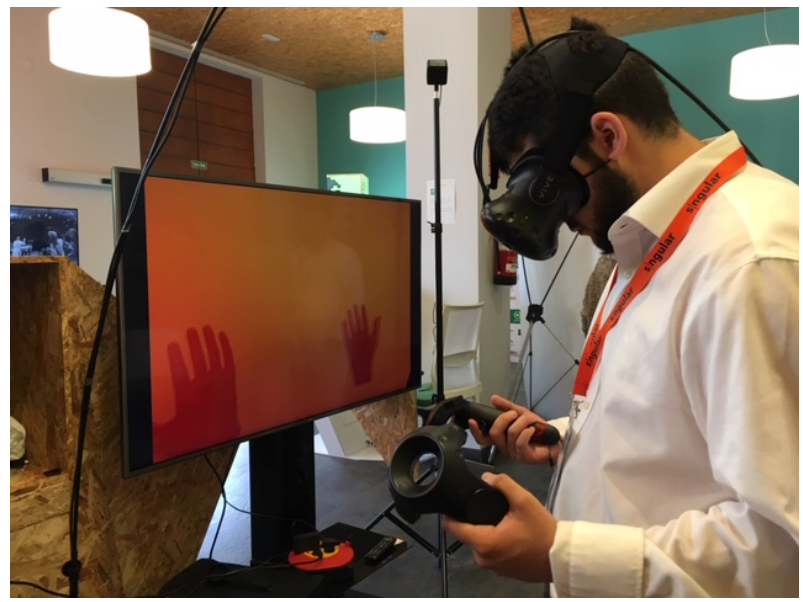

Figure 3: People testing the Ann Veronica Janssens's prototype yellowbluepink, 2015. Polo de contenidos digitales, Málaga, July, 2019.

These models were shown in July 2019 at the New Tech Observatory in Malaga. Different people who used it explained what they felt while they were inside the space. The emotions were diverse (from overwhelm to relaxation or pleasure, as well as disorientation or panic). At the moment the implementation of information is in process, since I 
am carrying out the analysis of more than 700 essay texts of specific catalogues of previously selected artists based on the heterogeneity of their light work. One of the objectives, in addition to the creation of the Virtual Reality environment to visit on site, seeks to create a conceptual linguistic corpus and a data base that establishes similar concepts between the descriptions of these works by the authors of the corresponding essays. This information together with the formal one of the traditional catalogue will be part of a new VR tool that combines technical information and aesthetic reception information. The aim of this research is to improve the aesthetic reception of this type of interventions, creating new knowledge around them to evaluate the cognitive and affective behaviour of the subject as an agent of somatic experimentation and cognitive-visual.

\section{REFERENCES}

Butterfield, J. (1993) The art light + space. Abeville Press, New York.

Mather Uchill, J. (2016) Experience, culture, cognition and the common sense. MIT Press, Cambridge, MA.

Maturana, H. and Berden-Zöller, G. (2012) The origin of humans in the biology of love. Andrews UK Limited, UK.

Ring Petersen, A. (2015) Installation. Art between Image and Stage. Museum Tusculanum Press, Copenhagen.

Suárez, J. I. (2020) Escenografía aumentada, teatro y realidad virtual. Editorial Fundamentos, Madrid.

Thompson, E. (2010) Mind in life. Biology, phenomenology and the sciences of mind. Harvard University Press, London.

Varela, F., Thompson, E. and Rosch, E. (1997) De cuerpo presente. Las cienciascognitiva y la experiencia humana. Editorial Gedisa, Barcelona. 